\title{
25 anos de Orçamento Participativo: algumas reflexões analíticas ${ }^{1}$
}

Lígia Helena Hahn Lüchmann²

\section{Resumo}

Originalmente do Brasil, o Orçamento Participativo (OP), notadamente o modelo de Porto Alegre criado em 1989, veio, ao longo do tempo, servindo como exemplo e referência de inovação democrática tanto no plano nacional como internacional, e instigando diferentes avaliações acerca de suas potencialidades e limites em promover mudanças sociais, culturais e político-institucionais. Tomando como base um conjunto de estudos sobre os Orçamentos Participativos (OPs), este trabalho pretende realizar um mapeamento dos debates sobre o tema buscando identificar, especialmente: a) as definições de OPs que são utilizadas na bibliografia; e b) as referências analíticas que têm sido utilizadas para a avaliação do surgimento, da sustentação e/ou do declínio das experiências, em diálogo com as principais variáveis que têm sido mobilizadas pelos estudos, em especial no Brasil, apontando que a diversificação de casos amplia as dificuldades de enquadramentos teóricos, estimula o desenvolvimento de esforços na construção de modelos el ou tipologias, e traz rebatimentos conceituais.

Palavras-chave: Orçamento participativo. Democracia. Sociedade civil. Desenho institucional.

\section{Introdução}

Como sabemos, dentre a lista de programas governamentais de cunho participativo, o Orçamento Participativo tornou-se internacionalmente reconhecido, na medida em que incorpora, por meio da criação de encontros e de regras institucionais, setores da populaçáo na dinâmica de discussão e de formulaçáo do orçamento público estatal. Nesta perspectiva, o Orçamento Participativo é apontado, atualmente, como uma das mais inovadoras experiências democráticas, ocupando um lugar privilegiado na lista dos exemplos

I Agradeço a leitura atenta e os comentários dos pareceristas anônimos da Revista, embora nem todas as sugestões tenham sido devidamente incorporadas ao artigo.

2 Professora do Departamento de Sociologia e Ciência Política e do Programa de Pós-Graduação em Sociologia Política da Universidade Federal de Santa Catarina (PPCSP/UFSC) e integrante do Núcleo de Pesquisas em Movimentos Sociais (NPMS/UFSC). Email: ligia@cfh.ufsc.br. 
recorrentemente saudados pelo campo de estudos sobre as inovaçóes democráticas no mundo contemporâneo. De acordo com Sintomer, Herzberg e Röcke (2008), as pesquisas sobre o Orçamento Participativo (doravante OP) estâo inseridas no campo dos estudos democráticos que "contains a wide range of participatory devices (consensus conferences, deliberative polls, citizen juries etc.), and a number of new concepts (empowered participatory governance, countervailing power, participatory publics, fourth power etc.)". De maneira geral, o OP é saudado não apenas por ser capaz de viabilizar os pressupostos mais centrais das perspectivas normativas da democracia, como a inclusáo política e a promoção da justiça social, como também por sua capacidade de reverter os crescentes - e preocupantes - índices de afastamento e de desconfiança política das populaçóes, expressos em abstençóes eleitorais, em diminuiçấo do envolvimento partidário e, inclusive, no declínio da militância junto aos sindicatos e em outras formas de associativismo social (DIAS; ALLEGRETTI, 2009).

O modelo do OP de Porto Alegre ${ }^{3}$ tem tido ampla repercussão no cenário nacional e internacional, seja por seu pioneirismo na construçáo de um complexo mecanismo de interlocução política com a população, seja pelo seu sucesso no que se refere à continuidade ao longo do tempo ${ }^{4}$. Mais ou menos inspirados no modelo de Porto Alegre, centenas de municípios no país e no exterior ${ }^{5}$ adotaram o OP. Embora as dificuldades de maior precisáo, os dados disponíveis indicam, no Brasil, a existência de $353^{6}$ municípios com OP. No plano internacional, estudo de Sintomer, Herzberg e Röcke (2012) aponta que havia, em 2010, entre 795 e 1.469 Orçamentos Participativos (OPs) operando em diferentes partes do mundo.

3 Em Porto Alegre, o OP teve início em 1989 na administração da Frente Popular (PT e PCB).

4 Mesmo com a mudança no governo municipal em 2004, com saida do PT e a entrada de José Fogaça (inicialmente do PPS e depois do PMDB), O OP não foi extinto, embora o novo governo tenha instituído outros programas, a exemplo do programa de Governança Solidária Local (GSL). De acordo com Rennó e Souza (2012), a mudança acarretou em perda de centralidade e de desempenho do OP no município.

5 De acordo com Sintomer, Herzberg e Röcke (2012, p. 80), "apesar das limitações, Porto Alegre tem sido a mais importante referência transnacional para o orçamento participativo e segue sendo uma das experiências mais fascinantes. O processo convenceu ativistas antiglobalização, assim como governos locais e assessores de organismos internacionais, como o Banco Mundial e o PNUD".

6 Dados de pesquisa realizada em 2012. Disponivel em: <http://www.redeopbrasil.com.br/home/>. 
Diante deste cenário, avolumam-se os estudos sobre os OPs no plano internacional, seguindo um padráo analítico que, como assinalado no trabalho de Sintomer, Herzberg e Röcke (2008), caracteriza-se pela ampliaçáo dos casos pesquisados e pelo refinamento de metodologias de bases comparativas. Essa ampliaçáo pode ser identificada nos estudos que visam apresentar panoramas mais abrangentes tanto no âmbito dos Estados nacionais (BASSOLI, 2012; MONTECINOS, 2011; RUESCH; WAGNER, 2013; DIAS; ALEGRETTI, 2009; GANUZA; NEZ; MORALES, 2013; BLAND, 2011; HE, 2011; YAN; WANG, 2012; McNULTY, 2012), como transnacionais (GOLDFRANK, 2006; SINTOMER; HERZBERG; RÖCKE, 2008; SINTOMER et al., 2010; GANUZA; BAIOCCHI, 2012; DIAS, 2013). Além disso, os estudos comparativos incluem náo apenas avaliaçóes entre OPs - seja da mesma regiáo ou país, seja entre casos de países diferentes (CABANNES, 2004; GOLDFRANK, 2006; MATOS; NEVES, 2008), como também entre OPs e outros formatos participativos, com focos analíticos variados (HOROCHOVSKI; CLEMENTE, 2012; D'ALBERGO; MOINI, 2007; GUGLIANO, 2004; AVRITZER, 2008; LÜCHMANN, 2008).

É certo que a ampliaçáo e a variaçáo de experiências são dadas pela variedade de contextos, colocando em xeque a qualificaçáo de muitas experiências como OP. Um dos impactos desse cenário de propagaçáo dos OPs diz respeito à sua própria definição. Afinal, como agrupar experiências tão diferentes em uma definição única? As respostas identificadas na literatura apontam pelo menos dois desdobramentos, quais sejam: a) A suavizaçáo do peso normativo de conceitos que, ancorados no modelo de Porto Alegre, ressaltam elementos de soberania popular, de autodeterminação, e de justiça social (AVRITZER, 2003; GANUZA; BAIOCCHI, 2012); b) A construçáo de tipologias que procuram agrupar e caracterizar os diferentes modelos em implementaçáo (SINTOMER; HERZBERG; RÖCKE, 2008, 2012; SINTOMER et al., 2010).

No caso mais específico do Brasil, embora também encontremos diversos trabalhos de cunho mais panorâmico e/ou comparativo (CARVALHO et al., 2002; RIBEIRO; GRAZIA, 2002; AVRITZER; NAVARRO, 2003; BORBA; LÜCHMANN, 2007; VITALE, 2004; MARQUETTI; CAMPOS; PIRES, 2008), os estudos sobre os OPs foram integrados em um campo mais amplo voltado para a análise das "instituiçóes participativas" 
(IPs), designação que inclui uma diversidade de espaços e mecanismos institucionais que incorporam cidadáos e/ou associaçôes em processos deliberativos de decisóes políticas, como conselhos gestores, conferências e planos diretores, além dos OPs (AVRITZER, 2008; PIRES, 2011). Nesse campo analítico, percebe-se um movimento em direçáo a avaliaçóes menos celebrativas. Alguns autores salientam que a literatura voltada para a análise de instituiçóes participativas no Brasil, em especial os OPs, vem atravessando diferentes fases - ou geraçôes - analíticas (SOUZA, 2011; SILVA, 2011), seguindo a dinâmica de criação e de institucionalizaçáo de OPs e de Conselhos Gestores a partir das décadas de 1980 e 1990. Grosso modo, se a primeira fase de estudos é apontada como distintiva por apresentar uma postura mais otimista na avaliaçáo das relaçóes positivas entre essas inovaçóes institucionais e a "democratizaçáo da democracia" (SANTOS, 2002), com o passar dos anos, o acúmulo de estudos e a incorporação de novos referenciais analíticos têm resultado em desdobramentos desse momento inaugural, em direçáo a leituras mais criteriosas que buscam o refinamento das bases teóricas e metodológicas de avaliação desses espaços.

Embora as diferentes frentes de investigaçáo, e em que pese a diversidade dos lócus institucionais (OPs, conselhos, conferências etc.) sob mira, a preocupaçáo com a avaliaçáo sobre os benefícios democráticos das instituiçóes participativas segue como referência analítica central, e vem se desenvolvendo no sentido de se identificar variáveis e mecanismos que operam na maior ou menor capacidade - ou sucesso - em provocar resultados que apontam para avanços democráticos, como a dimensão do associativismo, ou da sociedade civil; a vontade e/ou comprometimento político dos respectivos governantes; e o desenho institucional (LÜCHMANN, 2002; BORBA; LÜCHMANN, 2007; AVRITZER; NAVARRO, 2003; CARLOS, 2011; HOROCHOVSKI; CLEMENTE, 2012). Convém lembrar que, a depender do tipo institucional em foco, essas variáveis têm sido combinadas com outras dimensões, como, no caso dos OPs, a capacidade administrativa e financeira dos municípios que implementam processos participativos, os conflitos no campo do poder Executivo e/ou em suas relações com o Legislativo (DIAS, 2000; AVRITZER; NAVARRO, 2003; SOUZA, 2011; WAMPLER, 2005).

No entanto, uma leitura mais panorâmica da literatura mais recente demonstra que a maior ou menor capacidade explicativa desses fatores está 
diretamente relacionada com o modelo - e seu respectivo contexto - de OP sob investigaçáo. A vontade política ou a tradiçáo ou configuração da sociedade civil, por exemplo, perdem força explicativa em modelos capitaneados por organismos internacionais ou por forças políticas suprapartidárias e desenhados para a participaçáo individual. Além de trazerem à tona outras dimensóes investigativas, esses estudos também contribuem para a revisão e a "complexificação" dessas variáveis, motivando a ampliação e a interlocução entre os referenciais teóricos que vêm sendo mobilizados no campo da teoria democrática. Sáo essas revisóes que o presente trabalho pretende apresentar. $\mathrm{Na}$ primeira parte, aborda as principais definiçóes de OP que sáo utilizadas na bibliografia, apontando, além de algumas disputas conceituais, para o processo de esvaziamento da carga normativa do conceito original, em funçáo das características dos processos de ampliaçáo e de diversificaçáo dos modelos adotados no mundo. $\mathrm{Na}$ segunda parte, resgata e problematiza as principais referências analíticas que têm sido utilizadas para a avaliaçáo do surgimento, da sustentação e/ou do declínio das experiências, em diálogo com algumas variáveis que têm sido mobilizadas pelos estudos, em especial no Brasil.

\section{Definições e tipologias do Orçamento Participativo}

O modelo original de Porto Alegre inspirou o desenvolvimento de um conceito de OP que incorporou algumas das premissas centrais das teorias participativas e deliberativas da democracia, na medida em que estabeleceu novas relaçóes entre a sociedade civil e o Estado, relaçóes estas que foram estruturadas por um conjunto de regras e de procedimentos visando à inclusáo política e à promoção da justiça social. De acordo com "as regras do jogo" da democracia brasileira, tradicionalmente o poder Executivo possui a prerrogativa de iniciar e coordenar todo o processo de definição acerca dos tributos, das finanças e do orçamento público. O poder Legislativo apresenta, entre outras atribuiçóes, a prerrogativa de apreciar, apresentar emendas e aprovar a peça orçamentária do município, fiscalizando a sua execuçáo pelo poder Executivo. A participaçáo da população em todo esse processo limita-se, via de regra, à escolha dos representantes dos poderes Executivo e Legislativo através do sufrágio universal.

O Orçamento Participativo apresenta-se, portanto, como alternativa a essa dinâmica de elaboraçáo do orçamento público, na medida em que 
incorpora, por meio da criaçáo de mecanismos e de espaços de participaçáo direta e representativa, um amplo contingente da populaçáo. Em Porto Alegre, e experiência do OP teve início com a vitória da frente popular ${ }^{7}$ nas eleiçóes municipais de 1988, e passou gradativamente a se constituir na política central da administraçáo do município. Trata-se, certamente, de uma experiência que veio se alterando no tempo, e apresentando diversos conflitos e contradiçóes. $\mathrm{O}$ modelo resultante desse processo articula diferentes espaços de participação e de representação política, configurando um complexo e amplo desenho institucional voltado para a discussão e a deliberaçáo política acerca dos destinos de parte dos recursos públicos municipais. De acordo com Fedozzi (1996), o OP de Porto Alegre está sustentado em dois princípios básicos, quais sejam: regras universais de participação em instâncias institucionais e regulares de funcionamento; e um método objetivo de definiçáo dos recursos para investimentos, que perfazem um ciclo anual de atividades públicas voltadas para a confecçáo do orçamento do município.

Trata-se de um programa de governo que operacionalizou um processo misto, que combina participaçáo direta nas assembleias regionais com representaçáo dos delegados e conselheiros nos fóruns e no Conselho do OP. Neste sentido, embora incorpore uma dimensão participativa importante, o OP está diretamente relacionado com a dimensáo da representaçáo política, seja por sua ancoragem em estruturas de representaçáo (os delegados e conselheiros), aspecto geralmente negligenciado nas análises, seja por sua subordinação às regras, instituiçóes e atores do sistema democrático representativo. Neste sentido, e seguindo a avaliação de Fedozzi e Martins (2012), o uso de conceitos como "democracia direta" ou "esfera pública não estatal", entre outros, representa "uma versão ideológica e/ou normativa da experiência real do OP, já que supóe a ausência (irreal) do Estado na operacionalizaçáo dessa configuraçáo institucional, e superestima os componentes autônomos da ação dos atores da sociedade civil em relação ao Estado". Para os autores, o que caracteriza o OP é a cogestáo, na medida em que diz respeito a um "processo de construçâo compartilhada das regras para a distribuição dos recursos de investimentos e das regras do próprio sistema de participaçâo" (FEDOZZI; MARTINS, 2012, p. 17, grifos dos autores).

7 Coligação composta pelo Partido dos Trabalhadores (PT) e pelo ex-Partido Comunista Brasileiro (atual PPS). 
Um conjunto de elementos tem sido responsável pela classificação do modelo do OP de Porto Alegre como uma inovação democrática: a inclusão política; a subversáo do clientelismo e da corrupção; a promoçáo de transparência governamental; a redistribuiçáo dos recursos em prol dos setores mais carentes da populaçáo, promovendo, portanto, justiça social; e o aprendizado cidadáo (BAIERLE, 1992; ABERS, 1998; SANTOS, 1998; AVRITZER, 2003; WAMPLER, 2000; FEDOZZI, 1997, 2009; BAIOCCHI, 2001; CABANNES, 2004;AVRITZER, 2006; GOLDFRANK, 2006; SINTOMER; HERZBERG; RÖCKE, 2012; SINTOMER et al. 2010). Secondo e Lerner (2011), por exemplo, destacam seis benefícios do OP: "It deepens democracy, increases transparency, and promotes greater efficiency, increasing citizens' trust in government. It educates people about democracy and spending, and promotes social justice by leveling the playing field and directing resources to communides in need. Lastly, it helps build community, bringing neighbors together in pursuit of common goals". Mediante essas características, o modelo de Porto Alegre vem mobilizando a construçáo de um quadro conceitual que encontra ressonância nos arcabouços teóricos da democracia participativa e da democracia deliberativa.

Um dos conceitos mobilizados pela literatura é o de Empowered Deliberative Democracy (EDD) relativo às experiências que aspiram "to deepen the ways in which ordinary people can effectively participate in and influence policies that directly affect their lives [...] They have the potential to be radically democratic in their reliance on the participation and capacities of ordinary people, deliberative because they institute reason-based decision making, and empowered since they attempt to tie action to discussion" (FUNG; WRIGHT, 2001, p. 7). Trata-se de um conceito que resgata pressupostos deliberativos ancorados na troca de argumentos, nas condiçóes de igualdade e de pluralidade participativa (BAIOCCHI, 2001; AVRITZER, 2006). No entanto, alguns autores questionam a validade do referencial deliberativo para avaliar processos como os OPs, uma vez que, de maneira geral, os estudos deliberativos estão voltados para experimentos controlados como as "deliberative polls" ou os "citizen juries" ("minipúblicos"). Como apontado por Wampler (2012, p. 11), "What makes PB programs different from a program like Deliberative Polling is that it maintains people in their local contexts. It is not an artificial environment, divorcing people from the local nexus of their 
authority. Rather, citizens work in the local context to grapple with tough resource allocation decisions. They need to decide how to spend scarce public resources. Representante da corrente da democracia participativa, Pateman (2012) assinala que o OP, embora envolva deliberaçáo, é muito diferente dos experimentos deliberativos controlados, na medida em que abre a oportunidade para a participaçáo de todos os cidadáos da cidade. Neste sentido, segundo a autora, "PB is not a specially commissioned event for which a few citizens are chosen, but a regular part of a vital area of municipal government. Nor is it a supplement to existing democratic institutions. PB changes and democratizes the structure of one part of those institutions" (PATEMAN, 2012, p. 10).

Em que pese essas diferenças e disputas conceituais, o fato é que o modelo de Porto Alegre se tornou uma referência central na formulaçáo de uma perspectiva normativa de democracia ancorada nos pilares da inclusáo política e da justiça social. No entanto, essa perspectiva "forte" vem sendo crescentemente reformulada, ou suavizada, mediante um cenário de multiplicaçáo e de pluralização de experiências de OP, não apenas no Brasil, como no mundo. Sáo muitas as variaçóes, a depender do sistema político, do montante de recursos disponíveis, da cultura política, dos formatos institucionais. Um estudo sobre os OPs na Alemanha (RUESCH; WAGNER, 2013), por exemplo, aponta as especificidades do modelo predominantemente adotado naquele país: consultivo e com o objetivo de modernizar os governos locais e torná-los mais responsivos em um contexto de crise nas finanças municipais e de crescimento da insatisfaçáo e da abstenção eleitoral. "It was explicitly not their aim to introduce greater direct democracy. On the contrary, great importance was attached to ensuring that this participatory instrument did not curtail representative democracy in Germany, and that all decision-making competences remained with the elected political representatives of the people" (RUESCH; WAGNER, 2013, p. 37). Os casos de Portugal também apontam para algumas dessas características. Em geral, os OPs são consultivos, contam com uma autonomia limitada da sociedade civil, com uma "qualidade da deliberaçáo relativamente fraca e a falta de ênfase sobre o tema da justiça social” (DIAS; ALLEGRETTI, 2009, p. 76). No contexto chileno, Montecinos (2011) também adverte para a fragilidade dos OPs daquele país. Em muitos casos dependem fortemente da vontade política dos prefeitos, apresentam baixo grau de 
descentralização e de sustentação na sociedade civil e nos partidos políticos. Embora a Itália apresente casos mais próximos ao Brasil, estudo de Bassoli (2012) sugere, em funçáo do distanciamento com os requerimentos participativos e deliberativos, definir o OP como uma ferramenta administrativa e, portanto, melhor abrigado pela ideia de "participatory governance arrangements", um subtipo de "Local Governance Arrangement". Neste sentido, o OP seria um, entre outros, instrumento de governança local promovido pelas autoridades políticas, e que conta com a participação de cidadãos em um processo de argumentaçáo e deliberaçáo. De acordo com o autor, "considering that PB has been widely applied alongside other participatory instruments (so as to build participatory governance systems), it is possible to understand it as part of a wider phenomenon of civic empowerment" (BASSOLI, 2012, p. 1186).

Assim, a diversificação de casos amplia as dificuldades de enquadramentos teóricos, estimula o desenvolvimento de esforços na construçáo de modelos e/ou tipologias e traz rebatimentos conceituais. Os já citados estudos de Sintomer, Herzberg e Röcke $(2008,2012)$ são exemplares nesse sentido. Tendo em vista operacionalizar um estudo comparativo em escala internacional, os autores definem basicamente o OP como "a participaçáo de cidadáos nâo eleitos na elaboração e/ou alocação das finanças públicas" (SINTOMER; HERZBERG; RÖCKE, 2012, p. 75). No intuito de construir um padráo de referência diante de um cenário táo diversificado, os autores estabelecem uma definiçâo metodológica que inclui um conjunto mínimo de critérios ou requisitos necessários para identificação de uma experiência como OP:

(1) a dimensão financeira e/ou orçamentária deve ser discutida; o orçamento participativo lida com recursos escassos;

(2) o nível municipal deve estar envolvido ou, então, pelo menos, um distrito (descentralizado) com órgão representativo eleito e algum poder na administração pública (o âmbito de bairro não é suficiente);

(3) o processo deve ser recorrente (uma única reunião ou um referendo sobre questões financeiras não são exemplos de orçamento participativo);

(4) o processo deve incluir alguma forma de deliberação pública no âmbito de encontros/ fóruns específicos (a abertura de reuniões administrativas ou instâncias representativas clássicas para cidadãos "comuns" não é orçamento participativo);

(5) deve haver algum grau de prestação de contas com relação aos resultados (SINTOMER; HERZBERG; RÖCKE, 2012, p. 75). 
O mapa dos OPs confeccionado pelos autores (Figura 1 a seguir), aponta para a existência de aproximadamente 1.000 experiências que atendem, de forma muito variada, a esses requisitos. A identificaçáo dos casos permitiu a elaboraçáo de uma tipologia de OPs, segundo a sua origem, organização, caráter da deliberaçấo (consultiva ou decisória) e dimensôes da participaçáo (individual ou coletiva). A classificaçáo estabeleceu seis tipos de OPs denominados de: democracia participativa; democracia de proximidade; modernização participativa; participação de múltiplos atores; desenvolvimento comunitário; neocorporativismo. Em que pese algumas aproximaçóes e diferenças entre os tipos identificados, e as dificuldades, em alguns casos, de estabelecer limites mais claros entre eles, o que importa assinalar, aqui, é a referência ao modelo original de Porto Alegre. Assim, em uma ponta, temos as experiências que, seguindo este modelo original, atendem aos pressupostos da democracia participativa, ou da EDD, a exemplo da ampla participaçáo dos cidadáos, do poder (de fato) decisório, e da promoção da justiça social: "The interaction between a strong political will and bottom-up movements, a methodology that really implies a power devolution to community organisations, the possibility of good deliberation through the building of participatory councils, criteria of distributive justice and the mobilisation of the poor" (SINTOMER et al., 2010, p. 31). Na outra ponta, temos as experiências top-down que são consultivas e carecem da atuação de uma sociedade civil ativa e autônoma. "They rely on methodologies that do not give any real decision-making power or control to community organisations, which means they are highly unlikely to achieve an empowerment of the poor" (SINTOMER et al., 2010, p. 31). Entre essas duas pontas, várias experiências têm sido levadas a cabo, seja por setores da esquerda ou "NGOs that really want to change the development model, but lack the bottom-up mobilisation and a global political perspective" (SINTOMER et al., 2010, p. 31).

Essa variaçáo também repercute nos modelos teóricos de avaliaçáo acerca do sucesso ou fracasso dos OPs. Afinal, como reconhecem Sintomer, Herzberg e Röcke (2012, p. 102), uma democracia participativa requer "particularmente uma forte vontade política e uma sociedade civil mobilizada e independente, disposta a cooperar com governos locais". De acordo com Goldfrank (2006, p. 20), "la voluntad política, la competencia del personal, los recursos suficientes y un diseño informal, deliberativo y basado en reglas y necesidades, son características que parecen estar relacionadas com mayores probabilidades 
de PP exitoso. Además, las condiciones previas, los objetivos estratégicos y el diseńo institucional también parecen estar relacionados entre si”. Veremos, a seguir, como a ampliaçáo dos estudos, tanto no Brasil como no mundo, interpela essas variáveis, seja no sentido de que sua pertinência está relacionada com o modelo participativo em jogo, seja por adensarem complexidade analítica ao reconhecer outros elementos e relaçóes sociais e políticas envolvidas em processos como os OPs.

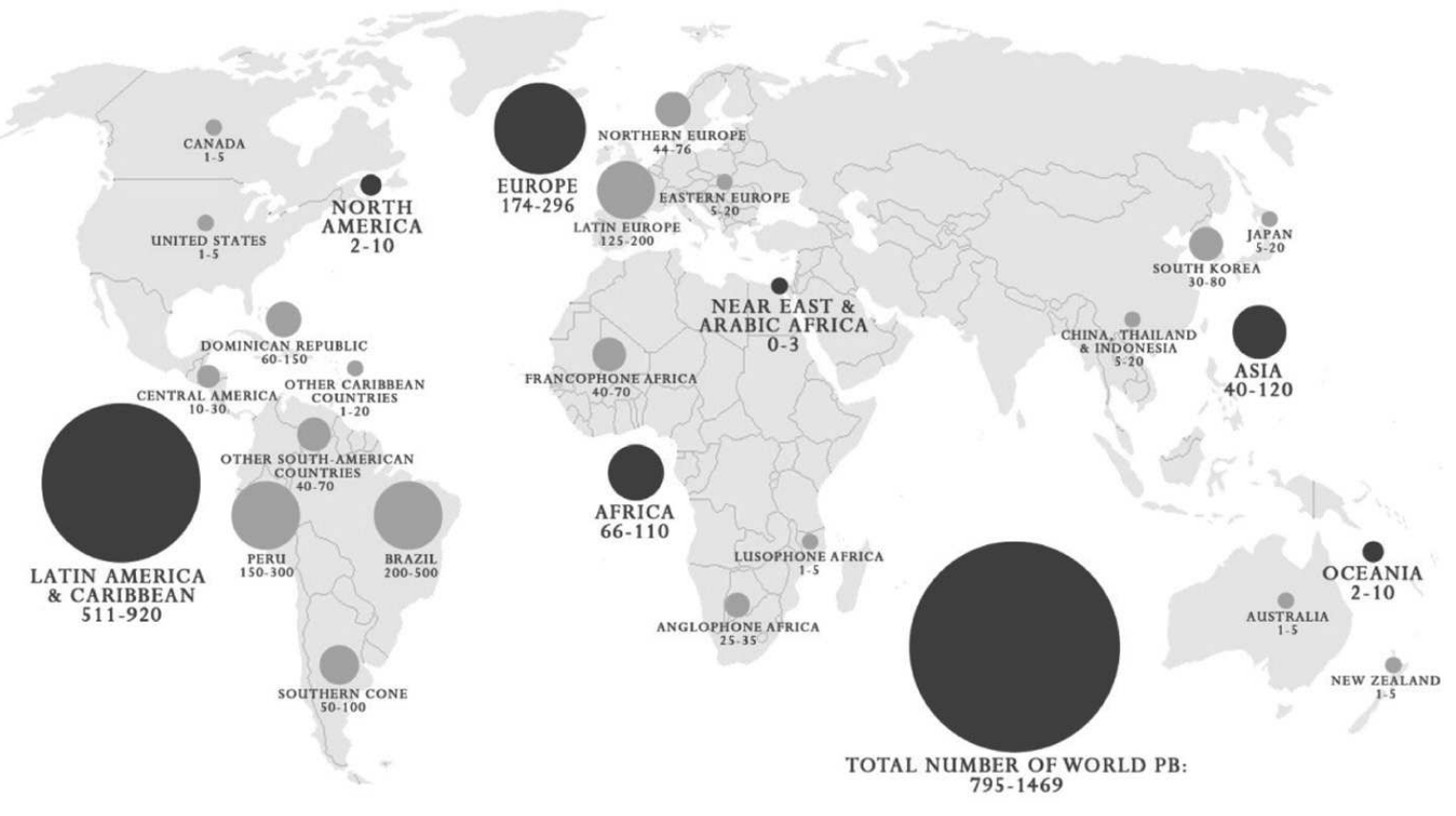

Figura I - Orçamento Participativo no mundo

Fonte: SINTOMER et al., 2012, p. 77.

\section{As condições de surgimento, sustentação e/ou declínio das experiências de OPs}

Como vimos, a proliferação dos OPs tem intercedido nas bases analíticas que vêm sendo construídas tendo como referência o modelo de Porto Alegre que se originou - e se desenvolveu - a partir de uma combinaçâo entre um projeto político de esquerda e uma sociedade civil atuante na cidade. A variaçáo de contextos e de modelos de OP aponta náo apenas para os limites explicativos de variáveis como a vontade política e a tradiçâo associativa, como para o próprio fato de que, como assinala Goldfrank (2006, p. 25), "ninguna de las interpretaciones captura la amplia variedad de los diseńos y los resultados". 
De fato, estamos falando, agora, de muitos OPs. O quadro apresentado pelos estudos comparativos assinala a extensáo e o distanciamento com o modelo original, ao ponto de nos perguntarmos se, diante deste cenário, é útil e desejável incluirmos programas tão diferentes em um mesmo conceito, por mais maleável que este possa ser. Os estudos assinalam que, se num primeiro momento o OP surge como uma "ideia de esquerda", sendo resultado, portanto, de uma forte vontade política motivada por um projeto político-partidário, os processos de expansão implicam em um afastamento das bases originais, seja no que diz respeito às suas origens, aos formatos organizativos, objetivos e setores sociais envolvidos.

Alguns estudos (CABANNES, 2004; DIAS; ALLEGRETTI, 2009) identificam as fases de expansão do OP como segue: a primeira (1989-1997) é caracterizada pela implementaçáo do OP em um pequeno número de cidades, especialmente no Brasil; a segunda (1997-2000) é marcada pela expansão no território brasileiro, "em que mais de 130 cidades adoptaram o orçamento participativo"; e a terceira (de 2.000 em diante) registra a expansão e a diversificação para fora do Brasil, por exemplo na Europa e em particular em municípios da Espanha, da Itália, da Alemanha, da Inglaterra e mais recentemente de Portugal, da Polônia e da Suécia.

Ganuza e Baiocchi (2012) identificam duas fases de expansão do OP (antes e depois do final de 1990): a primeira fase é caracterizada pela implementaçáo de um processo de reforma político-administrativa da esquerda (no Brasil e em alguns países da América Latina) compatível com princípios de justiça social e da boa governança, constituindo uma estratégia político-eleitoral que inova a administraçáo e intercede nas práticas clientelistas locais. No final dos anos de 1990, o OP entra em uma nova fase: "PB attracted international attention, becoming a best practice that was taken up by a number of international networks. Now, it traveled as a politically neutral device, one that could improve governance and generate trust in government" (GANUZA; BAIOCCHI, 2012, p. 2).

De fato, os estudos indicam uma variaçáo nas bases (atores e instituiçóes) que promovem o OP, tanto no Brasil como no mundo. Por um lado, o OP deixou de ser uma marca dos partidos de esquerda. No caso mais específico do Brasil, diversos partidos vêm adotando programas denominados de orçamento participativo, como analisado por Wampler (2008) ao definir duas 
fases do OP no país: a primeira fase (de 1989 a 1996), com o predomínio do PT sobre a implementaçáo dos OPs; e a segunda fase (de 1997 a 2004), com a diminuiçáo do peso do PT e o aumento progressivo de outros partidos políticos à frente (em dois terços) dos programas. Para além das fronteiras brasileiras, além da pluralidade partidária, testemunha-se também a entrada de novos atores na adoção de experiências de OPs. Para Sintomer et al. (2010), se a primeira geração, altamente politizada, estava voltada para a promoçáo de importantes mudanças sociais, outros atores, em especial o Banco Mundial e outras agências internacionais, passaram a implementar e/ou fomentar o OP em diferentes partes do mundo, impulsionando uma tendência de neutralização política que desafia a construçáo de análises mais sólidas no tocante aos impactos democráticos dessas práticas. Além disso, os estudos indicam a implementaçáo de OPs por iniciativa de outros setores políticos e sociais, a exemplo das experiências de Chicago e Nova York, originadas por vereadores (SECONDO; LERNER, 2011); ou de Guelph, no Canadá, levada a cabo por setores da sociedade civil local (PINNINGTON; LERNER; SCHUGURENSKY, 2009).

Muito embora haja o reconhecimento comum de que cada experimento descansa em determinada configuração social e política que imprime especificidades locais, alguns fatores têm sido considerados fundamentais para a emissáo de certificados democráticos às experiências. Allegretti e Herzberg (2004), por exemplo, sintetizam esses elementos, quais sejam: "la voluntad política que apoya la vía; la densidad asociativa y la capacidad autoorganizativa de los tejidos sociales; la coherencia y el refinamiento de los elementos de 'diseńo' organizativo del proceso; la capacidad administrativa y financiera del ente que experimenta" (ALLEGRETTI; HERZBERG, 2004, p. 17). Além disso, os autores assinalam para a importância dos contextos e das necessidades que mobilizam os experimentos. Se na América Latina as necessidades sociais motivam a implementaçáo de modalidades de OPs voltadas para a redistribuiçáo dos recursos territoriais, na Europa, em vários casos, as necessidades sáo de natureza política, orientadas para a modernizaçẫo e a eficácia da administraçấo pública.

Como já apontado anteriormente, a maior ou menor pertinência desses fatores depende da origem, dos propósitos e do modelo organizacional sob mira. De fato, OPs "fortes" (que promovem reformas político-administrativas 
compartilhando o poder decisório tendo como norte a justiça social, a inclusáo e o aprendizado político) parecem depender mais diretamente de uma vontade política disposta a destinar recursos, tempo e energia ao processo, bem como de uma sociedade civil organizada e atuante. O modelo de Porto Alegre é apontado como resultante de uma combinaçáo desse tipo, na medida em que foi capaz de construir um complexo mecanismo institucional por meio de articulaçóes entre lideranças do governo petista e de setores da sociedade civil local. No entanto, embora pertinentes, essas variáveis vêm sendo objeto de várias críticas e questionamentos, entre elas: a) um caráter voluntarista e, em boa medida, desconectado do campo político mais amplo e das relaçóes de interesse e de poder que perpassam as instituiçóes e os atores políticos e sociais (SOUZA, 2001; SOUZA, 2011; ROMÃO, 2011; WAMPLER, 2005; GOLDFRANK, 2006; ALLEGRETTI; HERZBERG, 2004); b) uma concepçấo normativa de sociedade civil que obscurece as suas diferenças e as relaçōes que mantém com a sociedade política, impedindo uma visáo relacional que reconheça e identifique os interesses e as estratégias de poder político que atravessam essas fronteiras (SILVA, 2006; DAGNINO; OLVERA; PANFICHI, 2006; ROMÁO, 2011; SOUZA, 2011); e c) uma ênfase dada, no caso do desenho institucional, às regras de funcionamento das instituiçóes participativas, desconsiderando, por um lado, o desenho dos campos do Executivo, do Legislativo e da configuraçâo dos partidos políticos que conformam a moldura mais ampla da arena dos conflitos que recobre esses espaços; e, por outro, os espaços, contatos, acordos e articulaçóes informais, e que ocorrem por fora das estruturas formais de instituiçóes participativas (WAMPLER, 2011; SOUZA, 2011).

É certo que a implementação de experiências ou programas governamentais, como sáo os casos de muitos OPs, depende, para ser bem sucedida, da vontade e do comprometimento dos respectivos governos ${ }^{8}$. Náo é à toa que

8 O comprometimento dos executivos na implantação e na sustentação da participação está relacionado não apenas com a sua centralidade no conjunto das ações governamentais, como também ao montante de recursos - humanos e materiais - que são destinados ao processo. Assim, o lugar que as instituições participativas ocupam na estrutura administrativa, o montante de recursos destinados à viabilidade de processos participativos, o compromisso e o respeito com as deliberações participativas, o envolvimento de representantes chaves da administração, a promoção de medidas de capacitação de participantes, a garantia de infraestrutura institucional são alguns dos indicadores dessa variável (LÜCHMANN, 2002; BORBA; LÜCHMANN, 2007). 
a grande maioria dos casos de criaçáo e de extinçáo segue o tempo de permanência no poder do grupo político que os sustentou. Assim, há vários estudos que mostram uma relaçáo positiva entre a derrota eleitoral e a extinçáo do OP. No entanto, estudos que avaliam a permanência no tempo (em gestóes consecutivas), apontam para a necessidade de complexificaçáo dessa variável. $\mathrm{O}$ estudo de Borba e Lüchmann (2007), por exemplo, ao constatar alguns dados de permanência e de extinçáo de OPs em municípios catarinenses, detectou a ocorrência de tensóes entre a vontade e o compromisso político; o efetivo controle governamental; e as dimensóes eleitorais. Percebendo um esvaziamento do OP ao longo do segundo e terceiro mandatos do governo, os autores sugerem que a extinçáo do OP ocorre náo apenas pela mudança do chefe do executivo municipal, mas também em função de alteraçóes nas coligaçóes partidárias e/ou na base de apoio governamental, em boa medida estendida para diferentes partidos em nome da "governabilidade". Por esta via, se as práticas de coalizão facilitam a negociaçáo e aprovação de projetos no Legislativo, também sáo responsáveis por descaracterizar e desqualificar a implementaçâo de inovaçóes participativas, ao trazerem para as equipes de governo atores políticos avessos a essas inovaçóes. Neste sentido, em nome da "governabilidade", muitas vezes sacrifica-se a possibilidade de mínima concretizaçáo de projetos "democrático-participativos" (BORBA; LÜCHMANN, 2007).

Em análise acerca da experiência de OP no governo de Marta Suplicy em São Paulo, Tatagiba e Teixeira (2006) ressaltam o sentimento de frustração dos participantes, seja pelo fato de as decisóes se concentrarem no gabinete da Prefeita, pelas críticas à fragilidade da representaçáo popular ("são sempre as mesmas pessoas que participam") e pelo uso político partidário deste espaço participativo, apontando para as tensôes e debilidades das relaçôes entre instituiçóes participativas e representativas, e alertando para uma combinação "cuja direçáo e sentido estão predominantemente orientados pelas exigências e desafios próprios à competição eleitoral. Trata-se [...] não de uma situação de complementaridade, mas de uma combinaçáo entre participaçáo e representação, sob a direçáo hegemônica dessa última" (TATAGIBA; TEIXEIRA, 2006, p. 234). O OP está inscrito nessa lógica, e sofre todas as consequências de uma institucionalidade ditada pela competição eleitoral.

Celina Souza (2001) também aponta importantes questionamentos sobre a tese da vontade política, em boa dose, vinculada a partidos de esquerda. De 
acordo com a autora, explicaçóes de base voluntarista tendem a pressupor "que é possível mudar a realidade pela ação de poucos grupos, em especial grupos náo hegemônicos no cenário decisório local ou nacional" (SOUZA, 2001, p. 95), desconsiderando, entre outros, as redes - de circunstâncias e de tradiçóes - que sustentam qualquer tipo de ação política.

Seguindo este foco analítico, e direcionando a atenção para as lacunas nos estudos sobre o OP, Luciana Souza (2011) analisa, a partir de pesquisa empírica comparando três experiências de OP desenvolvidas no interior do estado de São Paulo - Matáo, Rio Claro e São Carlos -, a importância e os desdobramentos dos padróes de relaçóes com os poderes Executivo e Legislativo, além dos partidos que compóem o governo, nas rupturas e permanências, ou nas diferentes trajetórias de programas de OPs. De acordo com a autora, "quando os desdobramentos dos padrôes de conflito examinados nas trajetórias estudadas levam a situaçóes de cooperaçáo entre os atores, como no caso de Sáo Carlos, a experiência do OP tem alcances maiores" (SOUZA, 2011, p. 282).

Ao avaliar os casos de Porto Alegre, Montevidéu e Caracas, Goldfrank (2006) ressalta a importância de fatores como, além do grau de descentralizaçáo da autoridade e a quantidade de recursos disponíveis, o quadro de organizaçáo e de institucionalização dos partidos de oposiçáo. Assim, se em Montevidéu e Caracas a forte oposição impeliu a adoçáo de mecanismos mais restritivos e subordinados às estruturas dos partidos dominantes locais, em Porto Alegre os partidos de oposiçáo náo lograram êxito, devido à baixa institucionalizaçáo partidária em articular uma reaçáo que ameaçasse a implementaçáo do OP da forma como foi desenhado no decorrer do tempo. Essa relaçáo com os partidos de oposiçáo também foi identificada no estudo de Wampler (2008) sobre as experiências brasileiras. Buscando avaliar a difusão do OP por outras siglas partidárias, o autor identificou que "os prefeitos parecem mais predispostos a adotar o OP em suas comunidades quando a esquerda ali é mais fraca [...] Uma redução no número de vereadores de esquerda leva a um aumento na probabilidade de que uma prefeitura adote o OP" (WAMPLER, 2008, p. 83). Neste sentido, o autor sugere que a adoçáo do $\mathrm{OP}$ por outros partidos náo alinhados à esquerda está relacionada com a avaliaçáo político-eleitoral do empreendimento. Desvincular o OP do PT e consolidar uma "reputação de reformistas orientados pela 'boa governança”" (WAMPLER, 2008, p. 84) pode ser uma estratégia política 
eficiente "onde a concorrência representada pelas forças de esquerda é mais débil” (WAMPLER, 2008, p. 84).

Assim, programas como o OP estáo subordinados não apenas às vontades e humores de governos eleitos, como também estáo sujeitos à lógica do sistema político e, por conseguinte, aos interesses e estratégias de outros setores e lideranças partidárias e do Legislativo. Como ressaltado por Goldfrank (2006, p. 18), além de atenderem a diferentes interesses políticos - em especial ganhar eleiçóes -, os resultados de inovaçóes como os OPs "no son necesariamente los que originalmente se esperan. Las consecuencias dependen no sólo de la intención de los diseńadores y de los contextos locales, sino de las intenciones y estratégias de otros actores, incluidos los oponentes políticos".

Além dessa dimensáo do campo político, os estudos também destacam a importância da dimensáo social, em especial, a configuração das práticas associativas e seu papel e atuação nas dinâmicas participativas. De maneira geral, a incorporaçáo dessa variável está ancorada na premissa de que o desenvolvimento e o acúmulo de relaçóes sociais horizontalizadas que estáo na base do associativismo sâo elementos centrais de ruptura com o clientelismo e o autoritarismo, na medida em que sem uma tradiçáo associativa, ou "sem o capital social, tenderiam a vigorar relaçóes clientelistas fundadas em relaçóes assimétricas, hierárquicas e verticais, com a consequente utilizaçâo de bens públicos como moeda de troca para se auferirem benefícios privados" (BOSCHI, 1999, p. 2). Seguindo essa mesma linha de raciocínio, Avritzer (2002), em análise das experiências de OP de Porto Alegre e de Belo Horizonte, afirma a importância da tradição associativa para a implementaçáo de experiências bem-sucedidas de democracia participativa. De acordo com o autor, "Porto Alegre tem uma formaçáo histórica mais ativa, com mais participação, menos relaçáo com mediadores políticos e maior mobilização dos próprios atores comunitários" ". O caráter associativo, reflexivo e autônomo da sociedade civil fundamenta a tese de que, quanto mais rica a vida associativa, maiores sáo as chances de implementaçáo de uma institucionalidade democrática direcionada para a mudança social e a generalização da cidadania.

9 A análise está ancorada em pesquisa realizada pelo autor que apresenta um conjunto de dados sobre práticas associativas no município. Confrontados com os dados de Belo Horizonte, o autor conclui que esta cidade, se comparada a Porto Alegre, "tem uma formação histórica mais conservadora, com menos mobilização e com maior preservação de mediadores politicos" (AVRITZER, 2002, p. 21). 
Neste processo de reconhecimento da importância da sociedade civil para a implementaçáo bem-sucedida de experiências e/ou instituiçóes participativas, ganha destaque a concepçáo habermasiana de sociedade civil (COHEN; ARATO, 1992; HABERMAS, 1997) caracterizada por um conjunto de sujeitos coletivos que tematizam novas questóes e problemas, que clamam por justiça social e que organizam e representam os interesses dos que são excluídos dos debates e deliberaçóes políticas. Aqui, a relação intrínseca entre sociedade civil e democracia está ancorada na tese de que as associaçôes civis são as instituiçóes responsáveis e especializadas na reprodução das culturas, das tradiçôes, na formaçáo de identidades coletivas e de práticas ancoradas nos princípios da solidariedade e da justiça social. Em se tratando de espaços participativos, como os OPs, a existência de uma sociedade civil crítica e autônoma é considerada central para a efetivaçáo de uma democracia efetivamente deliberativa e, portanto, ancorada em processos democráticos de expressão e formação da opiniáo sobre as necessidades e os destinos dos recursos orçamentais.

A adoção dessa perspectiva teórica, que relaciona de forma intrínseca os termos democracia, participaçáo e sociedade civil, está intimamente relacionada, no Brasil, ao fato de que foram (fundamentalmente, mas não exclusivamente) as organizaçóes desse campo as que lutaram pela implementação e institucionalização de espaços participativos de gestáo de políticas públicas no país. O caso de Porto Alegre segue como referência central (AVRITZER, 2002, 2006), embora esteja muito longe de ser considerado um modelo "bottom-up". Como ressaltado por Fedozzi e Martins (2012, p. 17), "Se, por um lado, o governo náo impôs sua visão unilateral ou simplesmente consultou a população, algo comum às práticas de participação tutelada pelo Estado, por outro lado, não delegou o poder instituinte das regras aos participantes, como supóem interpretaçóes mitificadoras do OP”.

Diversos trabalhos também apontam para os riscos e limites de concepçóes mitificadoras da sociedade civil que superestimam as qualidades democráticas de associaçóes, ONGs e grupos sociais (GURZA LAVALLE, 1999, 2003; DAGNINO; OLVERA; PANFICHI, 2006). Além da invisibilizaçáo da heterogeneidade, ou das diferenças e desigualdades no interior desse amplo e complexo campo de ação social, tais críticas também ressaltam o obscurecimento das relaçóes entre a sociedade civil e a sociedade política (ROMÃO, 2011; FEDOZZI, 2009, 2013). Afinal, as evidências empíricas vêm 
mostrando, entre outros, a heterogeneidade de objetivos, interesses e formas de organização; os vínculos, interesses e as estratégias com os setores políticos; e as influências do contexto na atuaçáo e formulaçáo política destes sujeitos coletivos, desautorizando uma leitura que imprime uma natureza necessariamente democrática desse campo.

No mapeamento dos estudos sobre os OPs podemos identificar, além da posiçáo analítica que aponta impactos positivos da sociedade civil sobre os OPs, posiçóes que, de formas variadas, apontam fragilidades na representaçáo política da sociedade civil, seja por identificar relaçóes clientelistas e de dependência para com o sistema político, seja por sua reação às ameaças de perda de um certo monopólio da representação da populaçáo com a introdução do OP'10, ou ainda, pela elitizaçáo através do predomínio, ou controle, por parte de determinadas organizaçóes sociais (BAIERLE, 2005; SILVA; BORBA; LÜCHMANN, 2007; McNULTY, 2012). Montecinos (2011) destaca, entre outros fatores, o escasso protagonismo da sociedade civil chilena nos processos de OP daquele país, bem como as relaçóes clientelistas entre associaçóes e os atores políticos municipais. No estudo sobre os OPs em Portugal, Dias e Allegretti (2009) ressaltam a forte dependência das variáveis estruturais relacionadas com o legado institucional (em especial, a tradiçáo centralizadora do poder político) e sociopolítico, caracterizado por baixa participação social. De acordo com os autores, "os movimentos associativos encontram-se muito sectorializados e pouco ou nada organizados, dificultando actuaçóes pró-activas em defesa de interesses globais. Náo raras vezes, estes movimentos vivem acoplados a dinâmicas partidárias que lhes retiram capacidade interventiva, credibilidade e abrangência na acção" (DIAS; ALLEGRETTI, 2009, p. 69).

O estudo de Baiocchi, Heller e Silva (2008), ao comparar municípios brasileiros (pares que adotam e náo adotam o OP) aponta para a existência de diferentes configuraçóes da sociedade civil nos diferentes municípios - em alguns casos formada por associaçóes clientelistas e/ou tuteladas e em outros casos mais engajadas e/ou autônomas. De maneira geral, o estudo apontou que a existência do OP produz impactos, porém limitados, nas respectivas sociedades civis locais: "It moves civil society from clientelist to associational

10 Vários estudos não fazem referência à sociedade civil em função dos contextos e dos modelos de OPs. Ver, por exemplo, os casos da Alemanha (RUESCH; WAGNER, 2013) e da China (HE, 20II; YAN; WANG, 20II). 
modes of demand-making, but does not contribute to the capacity of civil society to self-organize, at least in the short time period considered. Furthermore, the impact of $\mathrm{PB}$ is contingent on pre-existing configurations of civil society" (BAIOCCHI; HELLER; SILVA, 2008, p. 913).

De outra forma, o estudo de Ganuza, Nez e Morales (2013) comparando três casos de OPs em países diferentes (Porto Alegre, Córdoba e Paris), ao analisar os conflitos entre as autoridades públicas e a sociedade civil, mostra como a introduçáo do OP provoca reaçóes, em especial das associaçóes de moradores, na medida em que enfraquece o seu papel de mediação política entre a populaçáo e as autoridades políticas, deslocando o poder político para os espaços públicos de participação direta dos cidadáos. Diferentemente de outros formatos participativos que privilegiam a representaçáo das associaçóes $^{11}$, o OP abre a possibilidade da participaçáo aos cidadáos náo organizados. De acordo com os autores (GANUZA; NEZ; MORALES, 2013, p. 8), "This democratization also sketches out a different civil society, which neither rejects the role of secondary associations in the towns and cities, nor gives them special status as interlocutors". Em diálogo com postuladores da democracia associativa ${ }^{12}$, o estudo mostra que a alegada representatividade do associativismo náo é um fato dado. Ao contrário, é contestada por setores políticos e por cidadáos náo organizados. Neste sentido, "The problem for the associations is that the new model of participation takes them onto a plane of accountability, that is, they have to show they provide an effective voice for citizens as well as ideas and abilities that help to clarify debates" (GANUZA; NEZ; MORALES, 2013, p. 16).

Se esses estudos apontam as fragilidades e a diversidade da sociedade civil, além de desnudarem vínculos estreitos com a sociedade política, também apontam para as possibilidades de mudanças advindas da implementaçáo de espaços participativos. Em boa medida, essas mudanças sáo decorrentes do formato ou do desenho institucional. No caso dos OPs, faz diferença: se são consultivos ou decisórios; se incorporam os cidadãos ou as associaçóes; se instituem assembleias e encontros nos diferentes espaços territoriais ou se centralizam o espaço deliberativo; se são legais ou informais.

11 A exemplo dos Conselhos Gestores no Brasil, além de alguns OPs.

12 Representada por autores como Hirst (1994, 200I) e Cohen e Rogers (1995), como veremos adiante. 
De maneira geral, o desenho institucional configura-se como o conjunto de regras, critérios, espaços, normas, leis, que operacionalizam a participação e respondem, em boa medida, pela sua maior ou menor capacidade inclusiva e deliberativa. Como sabemos, os desenhos institucionais são resultantes de diversos fatores, variando de acordo com os objetivos, a composiçáo dos atores sociais e governamentais, as correlaçóes de forças e de interesses, o setor da política participativa, e a sua inserçáo no campo de poder político institucional.

Diversos estudos ressaltam algumas características institucionais do OP: tratam de necessidades mais imediatas da população; sâo autorregulados; instituem padróes redistributivos de recursos, estimulam a participaçáo individual; são consultivos e deliberativos; contam com assembleias territoriais e temáticas; promovem medidas de inclusáo de setores sociais mais excluídos; adotam regras de representação de delegados e conselheiros; e dispóem ao público maior acesso às regras e informaçóes (AVRITZER, 2003; BORBA; LÜCHMANN, 2007; FEDOZZI, 1996; GOLDFRANK, 2006). Uma das resultantes é o aumento da participaçáo de pessoas de baixa renda e escolaridade e de mulheres (BAIERLE, 2005; FEDOZZI, 2007; FEDOZZI et al., 2013; LÜCHMANN; BORBA, 2008), embora permaneçam as dificuldades e os desafios em incluir os setores mais jovens e que se situam na condição de extrema pobreza (FEDOZZI et al., 2013; SILVA; FEDOZZI, 2013). Assim, em que pese o fato de que "não se alteram relaçóes seculares pela simples mágica de um novo desenho institucional” (BAIERLE, 2005, p. 22), os esforços político-sociais e as regras que conformam o desenho institucional sáo importantes elementos para entendermos a maior ou menor capacidade participativa e deliberativa de instituiçóes participativas, seja pelos critérios e mecanismos de mobilização e de composição, constrangendo alguns setores e estimulando outros; seja pelas regras de distribuiçáo dos recursos; de formaçáo das agendas; dos processos de escolha de representantes; dos espaços de participaçẫo, entre vários outros indicadores. O perfil dos participantes é, em boa dose, definido pelos seus respectivos desenhos institucionais, responsáveis, portanto, pela maior ou menor inclusáo e pluralizaçáo da participaçáo e da representaçáo ali exercida ${ }^{13}$. Regras relativas à composiçáo dos conselhos

13 Não é à toa que algumas experiências de OP têm apresentado maior capacidade de mobilização e de ampliação da participação, especialmente dos setores mais populares. Não apenas por vincular, de forma direta, a participação com a obtenção de beneficios, como também em função de seu desenho institucional 
do OP também sáo importantes na avaliação da maior ou menor capacidade de influência e de vocalização dos diferentes atores participativos. No caso do Peru, por exemplo, onde os OPs sáo voltados para a participaçáo das organizaçóes da sociedade civil, ocorre um processo de elitização da participação com a consequente dificuldade de inclusão de organizaçōes e setores mais informais (McNULTY, 2012).

A implementaçáo do OP digital tem se constituído como mais um mecanismo de inclusáo, e que complexifica os estudos sobre o desenho institucional $^{14}$. O trabalho de Sampaio, Maia e Marques (2010) é um exemplo dos esforços em avaliar as possibilidades analíticas dos desenhos dos OPs digitais como ferramentas capazes de "valorizar mais ou menos a participaçáo popular, a conversação cívica ou a promoção de informação no ambiente digital, refletindo, por sua vez, o comportamento do agente político responsável pela criação do espaço" (SAMPAIO; MAIA; MARQUES, 2010, p. 451).

Lopes e Allegretti (2012), ao apresentarem o panorama dos casos de OP em Portugal, procuram avaliar os elementos responsáveis pela instabilidade, ou fragilidade ${ }^{15}$ dos programas, especialmente em sua capacidade de se manterem ao longo do tempo. De acordo com os autores, a extinção dos programas de OP pode ser explicada por alguns fatores, como problemas econômicos que afetam a disponibilidade de recursos para a realizaçáo de obras; mudanças na agenda política; e alteração de partidos no governo via processos eleitorais. No entanto, as variaçóes nas diferentes experiências apontam para a importância de um outro fator - mais interno - e que diz respeito ao modelo adotado, se mais consultivo "where people were invited to discuss problems and proposals, but the mechanisms of decision-making on investments were left to the sole responsibility of local governments"; ou codecisório, "where (by many

- que oportuniza a participação de indivíduos e associações nos bairros e regiões - diminuindo os custos de participação (LÜCHMANN; BORBA, 2008). Além disso, "various cities are taking affirmative action to foster the participation of women and other excluded groups" (CABANNES, 2004, p. 38).

14 Vários estudos sobre o OP digital podem ser encontrados na biblioteca virtual sobre o OP: <http:// brazilianparticipatorybudgeting.wordpress.com/category/I-biblioteca-virtual-sobre-op-bvop/s.

15 "By fragility we refer mainly to permanent interruptions in the experiments causing different phenomena of brittle fracture, that is, cases were PB experiences are abandoned or discontinued. However PBs do not always disappear suddenly; sometimes they suffer a drastic change in their impacts/coverage in a short time. When those transformations are in the direction of diminishing a PB incidence, than we can consider that there is Volatility" (LOPES; ALLEGRETTI, 2012, p. 2) 
different methodologies) citizens can give a say on the final budget design (regarding the percentage/amount designated to PB)"(LOPES;ALLEGRETTI, 2012, p. 10). Assim, o modelo adotado é um fator importante para avaliar o sucesso ou fracasso na capacidade de manutenção de experiências participativas ao longo do tempo, em especial a sua "solidez" em termos democráticos, ou o seu papel e seu escopo - se efetivamente participativo - nos processos decisórios. Faz diferença, portanto, a estrutura e o grau de alcance não apenas das decisóes, como da populaçâo envolvida em processos participativos.

\section{Considerações finais}

Transcorridos 25 anos desde a sua fundaçáo, o OP de Porto Alegre segue sendo reverenciado como modelo exemplar de inovaçâo democrática. Mais ou menos inspirados no modelo de Porto Alegre, centenas de municípios no país e no exterior têm adotado o OP, o que tem motivado o aumento dos estudos sobre esta temática em diferentes partes do mundo. Um dos impactos desse cenário de propagação dos OPs diz respeito à sua própria definição. Afinal, como agrupar experiências táo diferentes em uma definiçáo única? As respostas identificadas na literatura apontam pelo menos dois desdobramentos. Por um lado, a suavização do peso normativo de conceitos ancorados no modelo de Porto Alegre e a construçáo de tipologias que procuram agrupar e caracterizar os diferentes modelos em implementaçáo. Por outro lado, a necessidade de revisão e complexificação das leituras ancoradas em modelos que enquadram, ou congelam, determinados atributos ou dimensôes, invisibilizando dinâmicas e elementos que extrapolam as fronteiras de suas definiçóes. Modelos como os de democracia direta, democracia participativa, democracia deliberativa, democracia associativa ou democracia representativa comparecem no centro dessas tensóes, embora se vislumbre algumas propostas de aproximaçóes.

Tendo em conta esse debate, o artigo sugere que, por combinarem: participação e representaçáo; participação individual e coletiva; consulta e deliberação, modelos como o OP de Porto Alegre desafiam maior diálogo e interlocução, especialmente entre os referenciais ancorados na participaçáo, deliberação e representaçáo, seguindo uma orientaçáo da literatura mais recente que vem buscando superar visóes dualistas que posicionam esses diferentes instrumentos de ação política, em especial participação e representação, em lados opostos. 
Trazer as especificidades da representação em instituiçóes participativas contribui para revelar em que medida essas práticas estáo cumprindo o ideal democrático de ampliaçáo de canais de acesso político, ou se, ao contrário, acabam exacerbando déficits de representaçáo por meio de processos que privilegiam determinados grupos ou setores sociais. De outra forma também contribui para avaliar a legitimidade dos seus representantes delegados e conselheiros.

Embora as diferentes frentes conceituais e de investigaçáo, e em que pese a diversidade dos modelos de OP sob mira, a preocupaçáo com a avaliação sobre o seu potencial de promover inovaçáo democrática segue como referência analítica central, e vem se desenvolvendo no sentido de se identificar variáveis ou condiçóes de viabilidade e sustentaçáo, como a dimensão do associativismo, ou da sociedade civil; a vontade e/ou comprometimento político dos respectivos governantes; e o desenho institucional, além de questões referentes ao grau de descentralizaçáo político-administrativa e da capacidade financeira dos municípios. No entanto, a literatura mais recente traz à tona outras dimensóes investigativas, contribuindo para a revisão e a complexificação dessas variáveis e motivando a ampliaçáo e a interlocução entre os referenciais teóricos que vêm sendo mobilizados no campo da teoria democrática.

No caso das relaçóes com o sistema político mais amplo, os estudos apontam para a importância de se avaliar as influências do jogo político sobre a dinâmica dos OPs, o espaço que estes ocupam e os impactos que provocam na estrutura político-administrativa, além de considerar a sua relaçáo com outros canais de participaçáo geralmente existentes nas cidades. Assim, os OPs estâo inseridos no sistema político, e estão subordinados não apenas às vontades e humores de governos eleitos, como também às estruturas e estratégias do campo político institucional, traduzidas por diferentes dimensóes como a distribuiçáo da autoridade nos níveis federativos, a lógica de coalizóes e dos interesses eleitorais, a conformaçáo - e o grau de complexidade e de abrangência - do campo das políticas públicas e dos setores da burocracia estatal. Além disso, sua força depende dos respectivos desenhos institucionais e da trajetória e configuraçáo do campo dos atores sociais.

\section{Referências}

ABERS, R. From clientelism to cooperation: local government, participatory policy, and civic organizing in Porto Alegre, Brazil. Politics and Society, v. 26, p. 511-37, 1998. 
ALLEGRETTI, G.; HERZBERG, C. Participatory budgets in Europe: between efficiency and growing local democracy. Amsterdam: Transnational Institute and the Center for Democratic Policy-Making, 2004. Disponível em: <http://www.tni.org/sites/www.tni.org/archives/reports/ newpol/participatory.pdf>. Acesso em: 20 jan. 2014.

AVRITZER, L. Sociedade civil, espaço público e democratizaçáo: uma análise do orçamento participativo em Belo Horizonte e Porto Alegre. In: DAGNINO, E. Sociedade civil e espaços públicos no Brasil. São Paulo: Paz e Terra, 2002. p. 17-45.

O orçamento participativo e a teoria democrática: um balanço crítico. In: AVRITZER, L.; NAVARRO, Z. (Org.). A inovaçáo democrática no Brasil: o orçamento participativo. Sáo Paulo: Cortez, 2003.

New public spheres in Brazil: local democracy and deliberative politics. International Journal of Urban and Regional Research, v. 30, n. 3, p. 623-637, 2006.

Instituiçóes participativas e desenho institucional: algumas consideraçóes sobre a variaçáo da participaçáo no Brasil democrático. Opin. Pública, v. 14, n. 1, p. 43-64, 2008.

AVRITZER, L.; NAVARRO, Z. A inovaçáo democrática no Brasil. São Paulo: Cortez, 2003.

BAIERLE, S. G. Um novo princípio ético-político: prática social e sujeito nos movimentos populares urbanos em Porto Alegre nos anos 80. 1992. Dissertaçáo (Mestrado em Ciência Política) - Curso de Ciência Política, UNICAMP, São Paulo, 1992.

BAIERLE, S. Lutas em Porto Alegre: entre a revoluçáo política e o transformismo. Relatório de pesquisa. Porto Alegre: Mapas, dez. 2005.

BAIOCCHI, G. Participation, activism, and politics: the Porto Alegre experiment and deliberative democratic theory. Politics \& Society, v. 29, n. 1, p. 43-72, 2001.

BAIOCCHI, G.; HELLER, P.; SILVA, M. K. Making Space For Civil Society: Institutional Reforms and Local Democracy in Brazil. Social Forces, v. 86, n. 3, p. 911-936, 2008.

BASSOLI, M. Participatory budgeting in Italy: an analysis of (almost democratic) participatory governance arrangements. International Journal of Urban and Regional Research, v. 36, n. 6, p. 1183-1203, 2012.

BLAND, G. Supporting post-conflict democratic development? External promotion of participatory budgeting in El Salvador. World Development, v. 39, n. 5, p. 863-873, 2011.

BORBA, J.; LÜCHMANN, L. H. H. Orçamento participativo: análise das experiências desenvolvidas em Santa Catarina. Florianópolis: Insular, 2007. 
BOSCHI, R. R. Descentralizaçáo, clientelismo e capital social na governança urbana: comparando Belo Horizonte e Salvador. Dados, Rio de Janeiro, v. 42, n. 4, 1999.

CABANNES, Y. Participatory budgeting: a significant contribution to participatory democracy. Environment and Urbanization, v. 16, n. 1, p. 27-46, 2004.

CARLOS, E. Associativismo e desenho institucional no orçamento participativo da regiáo metropolitana do Espírito Santo. Ciências Sociais Unisinos, v. 47, n. 2, p. 116-128, maio/ago. 2011.

CARVALHO, M. do C. A. et al. Orçamento participativo nos municípios paulistas: gestão 1997-2000. São Paulo: Pólis, 2002. 32 p. (Cadernos Pólis, 5).

COHEN, J.; ARATO, A. Civil society and political theory. Cambridge: The Mit Press, 1992.

COHEN J.; ROGERS, J. Associations and democracy. London: Verso, 1995.

COHEN, J. Deliberation and democratic legitimacy. In: BOHMAN, J: REGH, W. Deliberative democracy: essays on reason and politics. Massachusetts: Institute of Tecnology, 1999.

D'ALBERGO, E.; MOINI, G. Political consequences of participative practices in an urban context: two case studies in Rome. Métropoles, n. 2, 2007.

DAGNINO, E.; OLVERA, A. J.; PANFICHI, A. Para uma outra leitura da disputa pela construção democrática na América Latina. In: DAGNINO, E.; OLVERA, A. J.; PANFICHI, A. (Org.). A disputa pela construçáo democrática na América Latina. São Paulo: Paz e Terra, 2006.

DIAS, M. R. Na encruzilhada da teoria democrática: efeitos do orçamento participativo sobre a Câmara Municipal de Porto Alegre. 2000. Tese (Doutorado em Ciência Política)-IUPERJ, Rio de Janeiro, 2000.

DIAS, N.; ALlEGRETTI, G. Orçamentos participativos em Portugal: em busca de uma democracia de maior proximidade ou de uma racionalidade funcional? Cidades - Comunidades e Territórios, n. 18, p. 59- 78, 2009.

DIAS, N. (Org.). Esperança democrática: 25 anos de orçamento participativo no mundo. Portugal: In Loco, 2013.

DRYZEK, J. Foundations and frontiers of deliberative governance. NY: Oxford University Press, 2010.

FEDOZZI, L. J. Do patrimonialismo à cidadania participaçáo popular na gestáo municipal: o caso do orçamento participativo de Porto Alegre. 313 f. 1996. Dissertaçáo (Mestrado em Sociologia)-Curso de Pós-Graduação em Sociologia, Universidade Federal do Rio Grande do Sul, Porto Alegre, 1996. 
Orçamento participativo: reflexōes sobre a experiência de Porto Alegre. Porto Alegre: Tomo; Rio de Janeiro: FASE-IPPUR, UFRJ, 1997.

Observando o orçamento participativo de Porto Alegre. Porto Alegre: Tomo, 2007. Cultura política e orçamento participativo. Cadernos Metrópole, Sáo Paulo, v. 11, n. 22, p. 385-414, jul.-dez. 2009.

FEDOZZI, L.; MARTINS, A. L. B. Novas instituiçóes participativas, processos de elitização e o orçamento participativo de Porto Alegre. In: ENCONTRO ANUAL DA ANPOCS, 2012, Águas de Lindóia.

FEDOZZI et al. Orçamento participativo de Porto Alegre: perfil, avaliaçáo e percepçôes do público participante. Porto Alegre: Hartmann Editora, 2013. Disponível em: <www.observapoa. com.br>.

FUNG, A.; WRIGHT, E. O. Deepening democracy: innovations in empowered participatory governance. Politics \& Society, v. 29, n. 1, p. 5-41, 2001.

GANUZA, E.; BAIOCCHI, G. The power of ambiguity: how participatory budgeting travels the globe. Journal of Public Deliberation, v. 8, Iss. 2, art. 8, 2012.

GANUZA, E; NEZ, H.; MORALES, E. The struggle for a voice: tensions between associations and citizens in participatory budgeting. International Journal of Urban and Regional Research, v. 38, n. 6, p.2274-2291, Nov. 2014. (First published online, 1 Sept. 2013).

GOLDFRANK, B. Los procesos de 'presupuesto participativo' en América Latina: éxito, fracaso y cambio. Revista de Ciencia Política, v. 26, n. 2, p. 3-28, 2006.

GUGLIANO, A. Participação e governo local: comparando a descentralização de Montevidéu e o orçamento participativo de Porto Alegre. Sociologia, problemas e práticas, n. 46, p. 51- 69, 2004.

GURZA LAVALLE, A. Crítica ao modelo da nova sociedade civil. Lua Nova, n. 47, 1999.

Sem pena nem glória: o debate da sociedade civil nos anos 1990. Novos Estudos, CEBRAP, n. 66, 2003.

Após a participação: nota introdutória. Lua Nova, n. 84, p. 13-23, 2011.

GURZA LAVAlle, A.; HOUTZAGER, P.; CASTellO, G. Democracia, pluralização da representação política e sociedade civil. Lua Nova, n. 67, 2006.

HABERMAS, J. Direito e democracia: entre facticidade e validade. Rio Janeiro: Tempo Brasileiro, 1997. v. 2. 
HE, B. Civic engagement through participatory budgeting in China: three different logics at work. Public. Admin., Dev. 31, p. 122-133, 2011.

HIRST, P. Associative democracy: new forms of economic and social governance. Amhertz: University of Massachusetts, 1994.

. Can associationalism come back? In: HIRST, P.; BADER, V. (Ed.). Associative democracy: the real third way. London: F. Cass, 2001.

HOROCHOVSKI, R. R.; CLEMENTE, A. J. Democracia deliberativa e orçamento público: experiências de participaçáo em Porto Alegre, Belo Horizonte, Recife e Curitiba. Rev. Sociol. Polít., v. 20, n. 43, p. 127-157, 2012.

LOPES, M. A.; ALLEGRETTI, G. (In)stability, a key element to understand participatory budgeting: discussing portuguese cases. Journal of Public Deliberation, v. 8, Issue 2, article 3, 2012.

LÜCHMANN, L. H. H. Possibilidades e limites da democracia deliberativa: a experiência do Orçamento Participativo de Porto Alegre. 2002. Tese (Doutorado em Ciências Sociais)-Unicamp, Campinas, 2002.

A representação no interior das experiências de participaçáo. Lua Nova, n. 70, p. 139$170,2007$.

Participação e representaçáo nos conselhos gestores e no orçamento participativo. Caderno CRH, UFBA, v. 21, n. 52, p. 87-97, abr. 2008.

Modelos contemporâneos de democracia e o papel das associaçóes. Revista de Sociologia e Política, UFPR, v. 20, n. 43, p. 59-80, 2012.

LÜCHMANN, L. H. H.; BORBA, J. Participaçáo, desigualdades e novas institucionalidades: uma análise a partir de instituiçōes participativas em Santa Catarina. Ciências Sociais Unisinos, v. 44, n.1, p. 58-68, jan./abril 2008.

MACPHERSON, C. B. A democracia liberal: origens e evolução. Rio de Janeiro: Zahar, 1978.

MARQUETTI, A.; CAMPOS, G. A.; PIRES, R. (Org.). Democracia participativa e redistribuiçáo: análise de experiências de orçamento participativo. São Paulo: Xamá, 2008.

MATOS, A. R.; NEVES, D. Participaçáo pública, capacitaçáo e sistemas de accountability: experiências de orçamento participativo na América Latina e na Europa em comparaçáo. E-cadernos do CES, 2008. Disponível em: <http://www.ces.uc.pt/e-cadernos/media/documentos/ecadernos2/ ana_raquel_matos_e_daniel_neves.pdf>.

McNULTY, S. An unlikely success: Peru's top-down participatory budgeting experience. Journal of Public Deliberation, v. 8, Iss. 2, art. 4, 2012. 
MONTECINOS, E. Democracia participativa y presupuesto participativo en Chile: ¿̨Complemento o subordinación a las instituciones representativas locales? Revista de Ciência Política, v. 31, n. 1, p. 63-89, 2011.

NAVARRO, Z. O. Orçamento participativo de Porto Alegre (1989-2002): um conciso comentário crítico. In: AVRITZER, L.; NAVARRO, Z. (Org.) A inovaçáo democrática no Brasil: o orçamento participativo. São Paulo: Cortez, 2003.

PATEMAN, C. Participaçáo e teoria democrática. Rio de Janeiro: Paz e Terra, 1992.

Participatory democracy revisited. Perspectives on Politics, v. 10, n. 1, p. 7-19, 2012.

PINNINGTON, E.; LERNER, J.; SCHUGURENSKY, D. Participatory budgeting in North America: the case of Guelph, Canada. J. of Public Budgeting, Accounting \& Financial Management, v. 21, n. 3, p. 455-484, 2009.

PIRES, R. R. (Org.) Efetividade das instituiçóes participativas no Brasil: estratégias de avaliação. Brasília, DF: Ipea, 2011.372 p. v. 7.

RENNÓ, L. R.; SOUZA, A. A metamorfose do orçamento participativo: mudança de governo e seus efeitos em Porto Alegre. Revista de Sociologia e Política, v. 20, n. 41, p. 235-262, 2012.

RIBEIRO, A. C. T.; GRAZIA, G. As experiências de orçamento participativo no Brasil (19972000). Sáo Paulo: Paz e Terra, 2003.

ROMÃO, W. Conselheiros do orçamento participativo nas franjas da sociedade política. Lua Nova, n. 84, p. 219-244, 2011.

RUESCH, M. A.; WAGNER, M. Participatory Budgeting in Germany: Citizens as Consultants. 2013. Disponível em: <http://www.buergerhaushalt.org/sites/default/files/German_PB_final_ engl1.pdf\#overlay-context=en/start> . Acesso em: 24 jan. 2014.

SAMPAIO, R. C.; MAIA, R. C. M.; MARQUES, F. P. J. A. Participaçáo e deliberaçáo na internet: um estudo de caso do orçamento participativo digital de Belo Horizonte. Opin. Pública, v. 16, n. 2, p. 446-477, 2010.

SANTOS, B. S. Participatory budgeting in Porto Alegre: toward a redistributive democracy. Politics \& Society, v. 26, n. 4, p. 461-489, 1998.

Democratizar a democracia: os caminhos da democracia participativa. Rio de Janeiro: Civilizaçáo Brasileira, 2002.

SECONDO, D.; LERNER, J. Social our money, our decision: participatory budgeting takes root in New York City. Social Policy, p. 22-25, Winter, 2011. 
SILVA, M. K. Dos casos aos tipos: notas para uma apreensão das variaçóes qualitativas na avaliação das instituiçōes participativas. In: PIRES, R. R. (Org.). Efetividade das instituiçóes participativas no Brasil: estratégias de avaliaçáo. Brasília, DF: Ipea, 2011. 372 p. v. 7.

Sociedade civil e construção democrática: do maniqueísmo essencialista à abordagem relacional. Sociologias, UFRGS, v. 8, n. 16, p. 156-179, dez. 2006.

SILVA, J. R.; FEDOZZI, L. A vulnerabilidade social como desafio inclusivo da democracia participativa: um estudo sobre o orçamento participativo de Porto Alegre. In: ENCONTRO ANUAL DA ANPOCS, 37., 2013. Seminário Temático Democracia e Desigualdades.

SINTOMER, Y.; HERZBERG, C.; RÖCKE, A. Participatory budgeting in Europe: potentials and challenges. International Journal of Urban and Regional Research, v. 32, n. 1, p. 164-78, 2008.

Modelos transnacionais de participaçáo cidadá: o caso do orçamento participativo. Sociologias, v. 14, n. 30, p. 70-116, 2012.

SINTOMER, Y. et al. Learning from the south: participatory budgeting worldwide: an invitation to global cooperation. Dialog Global 25, 2010. Disponível em: <http://www. buergerhaushalt. org/wp-content/uploads/2011/02/LearningfromtheSouth-ParticipatoryBudgetingWorldwideStudy.pdf >. Acesso em: 27 jan. 2014.

SOUZA, C. Construçáo e consolidaçáo de instituiçóes democráticas: papel do orçamento participativo. Sáo Paulo Perspec., v. 15, n. 4, p. 84-97, 2001.

SOUZA, L. Orçamento participativo e as novas dinâmicas políticas locais. Lua Nova, n. 84, p. $245-285,2011$.

TATAGIBA, L.; TEIXEIRA, A. C. C. Participação e democracia: velhos e novos desafios. Civitas: Revista de Ciências Sociais, v. 6, n.1, p. 223-240, 2006.

THOMPSON, D. Deliberative democratic theory and empirical political science. Annual Review of Political Science, Palo Alto, v. 11, p. 497-520, June 2008.

VITALE, D. Democracia direta e poder local: a experiência brasileira do orçamento participativo. In: COELHO, V. S. P.; NOBRE, M. (Org.). Participaçáo e deliberaçáo. Sáo Paulo: Editora 34, 2004.

WAMPLER, B. A guide to participatory budgeting: the international budget projecct. 2000. Disponível em: <http://www.internationalbudget.org/resources/library/GPB.pdf>. A difusão do orçamento participativo brasileiro: "boas práticas" devem ser promovidas? Opiniáo Pública, Campinas, v. 14, n. 1, p. 69-95, 2008. 
Expandindo accountability através de instituiçóes participativas? In: LUBAMBO, C.; COÊLHO, D. B.; MELO, M. A. (Org.). Desenho institucional e participaçáo política. Petrópolis: Vozes, 2005. p. 33-62.

. Que tipos de resultados devemos esperar das instituiçōes participativas? In: PIRES, R. R. (Org.). Efetividade das instituiçóes participativas no Brasil: estratégias de avaliaçáo. Brasília, DF: Ipea, 2011. 372 p. v. 7.

. Participatory budgeting: core principles and key impacts. Journal of Public Deliberation, v. 8, Iss. 2, article 12, 2012. Disponível em: <http://www.publicdeliberation.net/jpd/vol8/iss2/art12>. WARREN, M. Citizen representatives. In: WARREN, M. E.; PEARSE, H. (Ed.). Designing deliberative democracy. The British Columbia Citizen's Assembly. Cambridge (UK): Cambridge University, 2008.

. When, where and why do we need deliberation, voting, and other means of organizing democracy? A problem-based approach to democratic systems. In: ANNUAL MEETING OF THE AMERICAN POLITICAL SCIENCE ASSOCIATION, august 30-september 2, 2012.

YAN WU, Y.; WANG, W. The rationalization of public budgeting in China: a reflection on participatory budgeting in Wuxi. Public Finance and Management, v. 11, n. 3, 2011.

Does participatory budgeting improve the legitimacy of the local government? A comparative case study of two cities in China. The Australian Journal of Public Administration, v. 71, n. 2, p. 122-135, 2012.

Recebido em 22.06.2014

Aprovado em 12.12.2014

\section{Years of Participatory Budgeting: Some Analytical Considerations}

\section{Abstract}

Having originated in Brazil, Participatory Budgeting (PB), notably the model created in Porto Alegre in 1989, has served as a reference for democratic innovation in Brazil and abroad, instigating different evaluations of its potential and limitations for promoting social, cultural and political-institutional changes. Based on a set of studies about PB, this paper maps the debates about the theme to identify: a) the definitions of PB that are used in the bibliography; and b) the analytical references that have been used for the evaluation of the rise, maintenance and or decline of the experiences, in dialog with the main variables that have been identified by the studies, in particular in Brazil.

Keywords: Participatory Budgeting. Democracy. Civil Society. Institutional Design 